\title{
DEPENDÊNCIA EMOCIONAL: UMA REVISÃO SISTEMÁTICA DA LITERATURA
}

\author{
Denise Catricala Bution
}

Instituto de Psiquiatria do Hospital das Clínicas da FMUSP

\author{
Amanda Muglia Wechsler \\ Centro Universitário UNIFAFIBE
}

\begin{abstract}
Resumo
A dependência emocional é um transtorno caracterizado por comportamentos aditivos em relacionamentos amorosos. Entretanto, ainda há debate se esta dependência seria considerada uma patologia, como denominá-la e quais sintomas a definiriam. Assim, o presente estudo visa realizar uma avaliação sistemática da literatura acerca do tema, revisando artigos anexados nas bases de dados Scielo, Portal de Periódico CAPES e Google Acadêmico, publicados entre 2000 e 2014. Após uma análise criteriosa, foram selecionados 20 estudos. Os resultados mostraram que a dependência emocional é definida como um transtorno aditivo, no qual o indivíduo necessita do outro para manter seu equilíbrio emocional. Sua etiologia está relacionada ao desenvolvimento do apego na infância, além de fatores culturais e filogenéticos. Os tratamentos indicados são: terapia individual, terapia grupal, grupos de apoio e livros de autoajuda. Algumas inconsistências entre os estudos são discutidas, apontando a necessidade de mais estudos na área a fim de elucidar estas questões.
\end{abstract}

Palavras-chave: Dependência Emocional; Dependência Afetiva; Dependência de Relacionamentos; Dependências Genuínas.

\section{EMOTIONAL DEPENDENCY: A SYSTEMATIC REVIEW OF LITERATURE}

\begin{abstract}
Emotional Dependency is a disorder characterized by addictive behaviors in romantic relationships. However, there is still controversy about whether this dependency should be considered pathological, as well as its appropriate denomination and the symptoms that would define it. This paper presents a systematic evaluation of the literature on emotional dependency, reviewing all the indexed articles in Scielo, CAPES, and Scholar Google databases, published between 2000 and 2014. After careful analysis, 20 studies were selected. The results show that emotional dependency is defined as an addictive disorder, in which the individual needs another to maintain his emotional balance. Its etiology is related to the development of attachment during childhood, in addition to cultural and phylogenetic factors. The indicated treatments are individual therapy, group therapy, support groups and selfhelp books. We point out some inconsistencies among the studies, showing the need for more research to elucidate these questions.
\end{abstract}

Keywords: Emotional Dependency; Affective Dependence; Relational Dependency; Genuine Dependence. 


\title{
DEPENDENCIA EMOCIONAL: UNA REVISÍON SISTEMÁTICA DE LA LITERATURA
}

\begin{abstract}
Resumen
La dependencia emocional es un trastorno caracterizado por comportamientos aditivos en las relaciones amorosas. Sin embargo aún hay debates sobre si esta dependencia sería considerada una patología, cómo denominarla y qué formas la definía. Así el actual estudio tiende a realizar una evaluación sistemática de la literatura sobre el tema, revisando artículos anejos en las bases de datos Scielo, Portal de Periódico CAPES y Google Académica publicados entre 2000 y 2014. Después de un análisis juiciosa, fueron seleccionados 20 estudios. Los resultados muestran que la dependencia emocional es definida como un trastorno aditivo, en el que el individuo necesita del otro para mantener su equilibrio emocional. Su etiología está relacionada al desarrollo de apego en la infancia, además de factores culturales y filogenéticos. Los tratamientos indicados son: terapia individual, terapia en grupo, grupos de apoyo y libros de autoayuda. Algunas inconsistencias entre los estudios se señalaron.

Palabras clave: Dependencia emocional; Dependencia afectiva; Dependencia de relacionamientos; Dependencias genuinas.
\end{abstract}

\section{INTRODUÇÃO}

Um sentimento que permeia muitas relações humanas é o amor. Esta emoção é alvo de diversos escritores, cientistas e filósofos, tanto em perspectivas otimistas, como Kant e Byron, como em pessimistas, tais como Goethe e Schopenhauer (Sánchez Aragón, 2007). O amor é também objeto de estudo de psicólogos sociais, pois faz parte das relações humanas. Dentre as diversas teorias psicológicas sobre o amor, Sternberg (1988) propõe a teoria triangular do amor, em que o descreve como resultado de três elementos: Intimidade, Paixão e Compromisso. A Intimidade refere-se ao sentimento de proximidade, ligação e conexão com o outro. A Paixão envolve a ânsia de se unir ao parceiro, sendo a expressão de desejos e necessidades como autoestima, amparo, afiliação, dominação, submissão e realização sexual. O último componente, Compromisso, consiste em dois aspectos que não necessariamente ocorrem concomitantemente: o primeiro é de curto prazo, que seria a decisão de amar ao outro e o segundo a longo prazo, referente ao compromisso de manter esse amor. Entretanto, apesar da divisão dos componentes do amor em apenas três categorias, estas, quando combinadas, podem resultar em diferentes tipos de amor.

Yela (1997) realizou uma revisão deste modelo, dividindo a Paixão em dois componentes: erótica e romântica. Assim, o modelo proposto consistiria em quatro elementos: Compromisso, Intimidade, Paixão Erótica e Paixão Romântica. A Paixão Erótica estaria relacionada à dimensão física e fisiológica do amor. Já a Paixão Romântica consistiria em ideias e atitudes impetuosas sobre o objeto amado, que seriam próprias da construção cultural do amor em nossa sociedade: pensamentos intrusivos, idealização, crença de que existe algo mágico na relação, identificação do companheiro com o ideal romântico de parceiro, entre outros. O fator Intimidade compreenderia aspectos recíprocos de um vínculo especial de união afetiva, tais como: apoio emocional, compreensão, 
entendimento, confiança, segurança e conforto junto ao companheiro. Por fim, o componente Compromisso referir-se-ia à decisão de manter o relacionamento apesar das dificuldades encontradas, devido ao apreço e estima sentidos pelo amado e pela própria relação.

Outro aspecto que tem recebido atenção dos estudiosos são os mecanismos neurológicos envolvidos nas relações amorosas. Observa-se que os sentimentos amorosos utilizam as mesmas vias neurais que substâncias psicoativas, ativando os sistemas de recompensa do cérebro (Fisher, Aron, \& Brown, 2005) e criando sintomas de dependência similares. Portanto, apesar do termo "dependência" ser tradicionalmente ligado ao uso de substâncias ou drogas psicoativas, as dependências de sentimentos (denominação utilizada por Moral e Sirvent, 2009) ou as Dependências de Relacionamentos (denominação proposta por Sirvent, 2000) também merecem ser objeto de pesquisa e intervenção, visto que apresentam etiologia e sintomatologia semelhante à de outras dependências. Neste sentido, a Dependência de Relacionamentos, segundo Sirvent (2000) seria caracterizada por comportamentos aditivos que teriam como base os relacionamentos interpessoais.

Bornstein e Cecero (2000) propõe que uma relação de dependência pode ser definida por quatro elementos: motivacional, afetivo, comportamental e cognitivo. O componente motivacional refere-se à necessidade de suporte, orientação e aprovação. O segundo componente, afetivo, está relacionado à ansiedade sentida pelo indivíduo diante de situações nas quais ele necessita agir independentemente. O componente comportamental alude à tendência a buscar ajuda de outros e de submissão em interações interpessoais. E o último componente remete à percepção do sujeito como impotente e ineficaz.

Assim, pode-se classificar as Dependências de Relacionamentos em dois tipos: (1) as Genuínas, quando apenas uma patologia relacionada à dependência afetiva está envolvida e (2) as Mediadas, quando o sujeito é adicto ou convive e depende de um. Dentre as Dependências Genuínas estariam: a Dependência Emocional, a Tendência Dependente, o Apego Ansioso, os Transtornos de Personalidade (entre eles, dependente, limítrofe e antissocial), etc. Já nas dependências mediadas estariam a codependência e a bidependência. A codependência ocorre quando um indivíduo não adicto estabelece um vínculo patológico e depende de outro sujeito, que por sua vez, é dependente de drogas ou álcool. Por sua vez, na bidependência, um indivíduo adicto estabelece uma relação dependente com outras pessoas, que podem ou não fazer uso de substâncias psicoativas (Sirvent, 2000).

Considerando-se esta categorização, o presente estudo teve como foco um subtipo de dependência genuína: a Dependência Emocional. Esta foi definida por Moral e Sirvent (2008) como um padrão crônico de demandas afetivas insatisfeitas, que buscam ser atendidas através de relacionamentos interpessoais caracterizados por um apego patológico. Apesar de essas dependências serem 
ignoradas por muitos profissionais, são muito frequentes no cotidiano clínico. Ademais, comumente figuram como comorbidades de outras psicopatologias, como depressão, transtornos alimentares e transtornos ansiosos (Arntz, 2005; Bornstein, 2012). A tudo isto soma-se o fato de que a maioria dos pacientes não busca ajuda e os que o fazem são, em sua grande maioria, mulheres (Sirvent, 2000). Portanto, nota-se que as dependências de relacionamentos se configuram como um campo de estudo ainda pouco explorado, necessitando de maiores investigações e maior unidade no que se refere aos termos utilizados, que são variados e pouco precisos em sua definição operacional. Dessa forma, o presente artigo teve como objetivo realizar uma revisão sistemática da literatura a fim de obter um panorama geral sobre a produção científica acerca da Dependência Emocional.

\section{MÉTODO}

Para atingir o objetivo proposto, foi realizada uma revisão sistemática da literatura através de um levantamento exclusivamente eletrônico nas bases de dados: Scientific Library Online (SciELO), Portal de Periódicos CAPES e Google Acadêmico. Foram selecionadas cinco palavras-chave, pesquisadas individualmente: "Affective Dependence", "Emotional Dependency", "Pathological Love" e "Love Addiction".

Os critérios de inclusão empregados foram: artigos científicos, publicados entre os anos de 2000 a 2014, nos idiomas Inglês, Português e Espanhol, quantitativos ou teóricos, cujos objetivos principais se referiam à investigação da dependência emocional. Os critérios de exclusão se referiram a pesquisas relacionadas à validação de instrumentos de avaliação psicológica, qualitativas e com participantes menores de idade. Também foram excluídos livros, teses e artigos não científicos. Incluíram-se apenas artigos referentes às dependências genuínas, ou seja, apenas dependências afetivas, sem o envolvimento de indivíduos que façam uso de substâncias químicas. Desta forma, foram excluídos artigos referentes a dependências mediadas, como a codependência e a bidependência.

A partir dos critérios de inclusão e exclusão, foram encontrados 3.635 artigos, sendo que, destes, apenas 2.506 artigos foram avaliados, devido à impossibilidade de acesso aos demais artigos em função da visualização permitida em cada base de dados. A seleção inicial destes artigos ocorreu através de seus títulos, sendo excluídos, neste processo, 2.183 artigos pelos seguintes motivos: 88 títulos eram duplicados, 91 artigos eram referentes a crianças e adolescentes, 639 eram teses, cartas, livros ou editoriais, 126 versavam sobre outras dependências como drogas e tabaco, 227 consistiam em análises de documentos artísticos, 120 abordavam diferentes patologias e psicopatologias, 59 abarcavam assuntos relativos à fisiologia, 41 foram escritos 
em idiomas não considerados nesta pesquisa, 587 não se referiam à dependência emocional, 1 estudo era anterior ao ano 2000, 144 se referiam à política e/ou ética e 60 eram sobre pedagogia. Por fim, obteve-se um total de 251 artigos para a segunda etapa de análise.

A segunda análise foi realizada através da leitura dos resumos de cada artigo. Nesta etapa, foram excluídos 216 artigos: 9 discorriam exclusivamente sobre apego, 27 eram relativos a outras dependências como drogas, álcool ou codependência, 2 estavam escritos em idiomas não abarcados por esse estudo, 7 versavam sobre biologia e fisiologia, 50 aludiam a relacionamentos amorosos e seus conflitos, 54 eram teses ou capítulos de livros, 6 eram relacionados a organizações, 14 consideravam outras patologias e psicopatologias, 39 abordavam violência, 6 consistiam na construção de instrumentos padronizados e 2 eram estudos de caso.

Assim, foram selecionados 35 artigos que passaram por uma terceira análise. Esta etapa consistiu na leitura integral dos artigos, eliminando-se 15 trabalhos: 5 estudos de caso, 1 sobre diferenciação entre vícios, 4 cujos objetivos não estavam relacionados à dependência emocional, 3 que falavam sobre a dependência a um indivíduo dependente e 2 artigos aos quais não foi possível ter acesso. Portanto, a amostra final desta pesquisa consistiu em 20 artigos científicos referentes à dependência emocional e/ou afetiva.

\section{RESULTADOS}

Os resultados descritivos dos artigos selecionados pela revisão sistemática encontram-se no Apêndice A. Dentre os artigos selecionados, treze (65\%) eram estudos empíricos e sete (35\%) eram trabalhos teóricos, sendo um de metaanálise, um de revisão sistemática da literatura e cinco revisões da literatura. Os estudos empíricos contaram com um total de 3.954 participantes, sendo os estudantes universitários o grupo mais analisado, representando $74 \%$ das amostras (2.916 sujeitos). Quanto à sua nacionalidade, os estudos estiveram distribuídos da seguinte maneira: seis eram dos Estados Unidos, quatro da Colômbia, dois da Austrália e um trabalho de cada país listado: Brasil, Irã, País Basco, Países Baixos, Espanha, Israel, Noruega e México. Observou-se um interesse crescente da comunidade científica sobre o assunto conforme pode ser observado na Figura 1, que demonstra que no período de 2000 a 2006 foram publicados sete artigos. Já no período entre 2007 e 2013 foram treze publicações sobre o tema. 


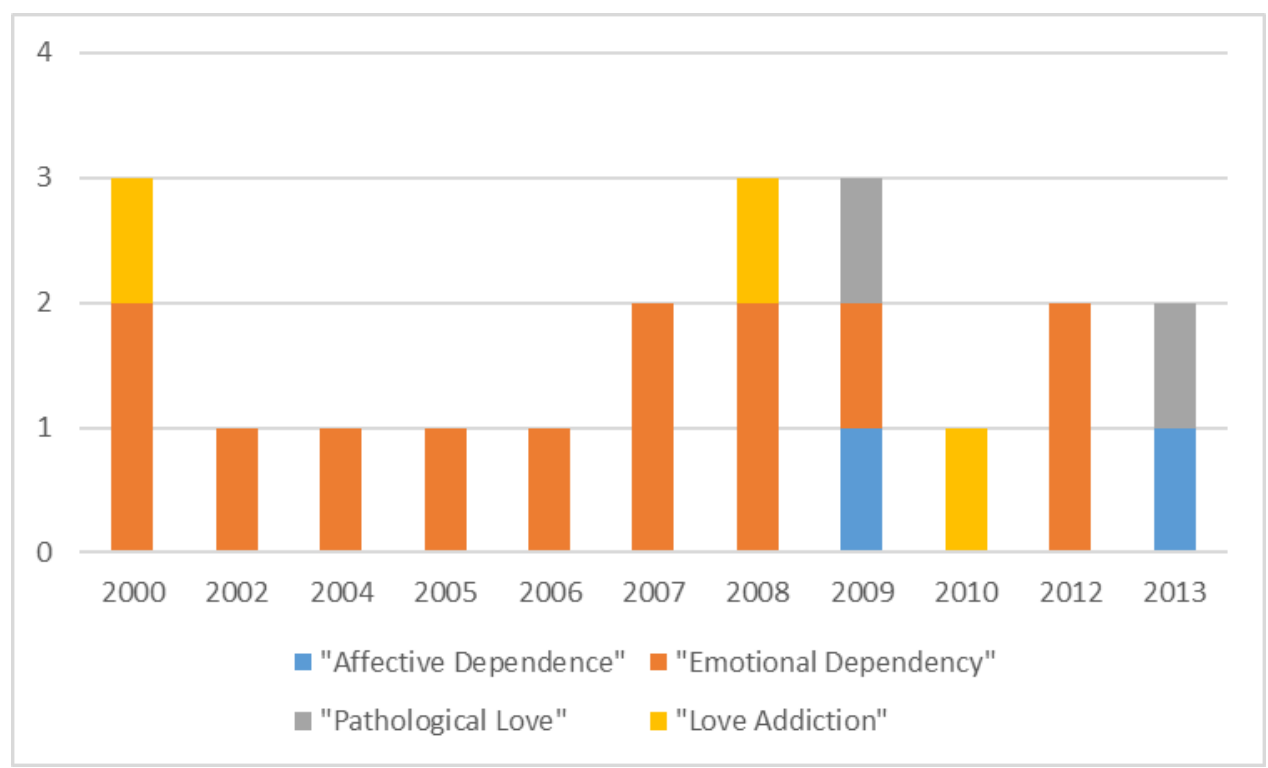

Figura 1. Frequência de artigos sobre dependência emocional e/ou afetiva publicados por ano.

Em relação aos trabalhos teóricos, três tinham como objetivo definir a dependência emocional abordando sua conceituação, etiologia e tratamento (Hoogstad, 2008; Izquierdo Martínez \& Gomes-Acosta, 2013; Sussman, 2010). Dois artigos discutiram a relação entre dependência emocional e violência (Bornstein, 2006, 2012), um relacionava a dependência emocional aos traços do modelo dos Cinco Grandes Fatores (Bornstein \& Cecero, 2000) e dois diferenciaram a dependência emocional de outros tipos de dependência: funcional (Arntz, 2005) e econômica (Bornstein, 2006).

Os trabalhos empíricos se dividiram da seguinte forma: três visavam traçar o perfil cognitivo dos dependentes emocionais (Jaller Jaramillo \& Lemos Hoyos, 2009; Lemos Hoyos, Londoño Arredondo, \& Zapata Echavarría, 2007; Lemos, Jaller, González, Díaz, \& De La Ossa, 2012), três investigaram a relação entre dependência e apego (Ahmadi, Davoudi, Ghazaei, \& Mardani, 2013; Alonso-Arbiol, Shaver \& Yárnoz, 2002; Franco \& Aragón, 2008) e dois pesquisaram sobre a relação entre violência e dependência emocional (Charkow \& Nelson, 2000; Kane, Staiger, \& Ricciardelli, 2000). Um artigo buscou realizar uma análise clínica a fim de diferenciar características de dependentes emocionais com relação a outros tipos de dependências de relacionamentos e da população geral (Moral \& Sirvent, 2009) e outro comparou um grupo com dependência emocional e um sem dependência emocional quanto à impulsividade, personalidade e satisfação em relacionamentos românticos (Sophia et al., 2009). Também foi abordada a relação entre a dependência emocional e outros assuntos, tais como: dependência instrumental, diferenças entre gêneros (Alonso-Arbiol et al., 2002), papéis nos relacionamentos amorosos (Charkow \& Nelson, 2000), ciúmes (Franco \& Aragón, 2008), modelo de dois 
componentes proposto por Livesley (Gude, Hoffart, Hedley, \& Rø, 2004), agressividade (Kane et al., 2000), timidez (Myers, Dilks \& Marceaux, 2007) e traços do modelo dos Cinco Grandes Fatores (Rubinstein, 2007). É importante ressaltar que estes objetivos se referem muitas vezes ao mesmo artigo, já que algumas publicações possuíam mais de um objetivo.

Apesar de utilizarem praticamente a mesma definição, os trabalhos divergiram quanto à nomenclatura utilizada. O termo mais empregado foi dependência emocional (9), seguido por dependência interpessoal (3), Transtorno de Personalidade Dependente (3), dependência amorosa (2), amor patológico (1), amor obsessivo (1) e dependência nos relacionamentos (1). Todos os autores que definiram a dependência emocional afirmaram que o indivíduo com este transtorno necessita do outro para estabilidade emocional (Hoogstad, 2008; Izquierdo Martínez \& Gomes-Acosta, 2013; Sussman, 2010).

Por outro lado, Arntz (2005) distinguiu os conceitos de dependência emocional e dependência funcional. A primeira seria caracterizada como uma necessidade de ligação emocional e um senso de cuidado com o outro. Já o dependente funcional poderia sentir-se incapaz de cuidar de si mesmo, necessitando de uma pessoa mais forte da qual possa depender. No entanto, ambos conceitos dizem respeito a uma relação afetiva patológica e dependente.

Quanto à etiologia, os autores (Hoogstad, 2008; Izquierdo Martínez \& Gomes-Acosta, 2013; Sussman, 2010) parecem concordar quanto à influência do desenvolvimento afetivo durante a infância nas relações amorosas futuras. Hoogstad (2008) afirma que é necessário que a criança cresça em um ambiente afetuoso e seguro, com aceitação incondicional, para que consiga desenvolver sua identidade de forma sadia. Assim, o apego, como comportamento aprendido durante a infância influenciaria nos relacionamentos da vida adulta, podendo levar o indivíduo a desenvolver relacionamentos sadios ou disfuncionais de acordo com a forma com que aprendeu a se apegar (Izquierdo Martínez \& Gomes-Acosta, 2013; Sussman, 2010).

Três estudos procuraram verificar a relação entre os estilos de apego e a dependência emocional. Encontrou-se uma correlação positiva entre o apego preocupado e a dependência emocional (Alonso-Arbiol et al., 2002; Franco \& Aragón, 2008) e entre o apego ambivalente e a dependência emocional (Ahmadi et al., 2013, Sophia et al., 2009). Já aqueles indivíduos não diagnosticados com dependência emocional apresentaram predominantemente o apego seguro (Sophia et al., 2009). Entretanto, Alonso et al. (2002) afirmaram existir uma forte correlação negativa entre o apego evitativo e a dependência emocional, enquanto que Franco e Aragón (2008) sugeriram existir uma correlação forte e positiva entre estes dois construtos.

Dois fatores que também podem contribuir para o desenvolvimento da dependência emocional estariam relacionados aos níveis de seleção filogenético e cultural. O primeiro seria o componente neurobiológico, que explicaria a 
dependência emocional a partir de uma fixação na superativação neuronal, frequente no início de relacionamentos; ou seja, o indivíduo necessitaria dessa atividade neuronal aumentada para se sentir confortável em seu relacionamento atual. O segundo fator seria o cultural, associado principalmente à mídia, que retrata o amor como algo idealizado, sinalizando como um comportamento comum a obsessão e a dependência exagerada do objeto amado (Sussman, 2010).

Quanto à prevalência da dependência emocional, não houve consenso entre as pesquisas: Sussman (2010), a partir de uma revisão da literatura, afirmou que entre $5 \%$ a $10 \%$ da população seria dependente emocionalmente. Ahmdi et al. (2013) verificaram que 17,9\% de uma amostra de 290 pessoas apresentou dependência emocional. Outros estudos obtiveram uma porcentagem de $24,6 \%$ da amostra estudada com tal patologia (569 sujeitos) (Lemos et al., 2012; Jaller Jaramillo \& Lemos Hoyos, 2009). Gude et al. (2004) afirmam que essas discrepâncias ocorrem principalmente em função do tipo de participantes utilizados nas pesquisas, ressaltando que a incidência do transtorno de personalidade dependente varia de $17 \%$ em pacientes internados, $29 \%$ em pacientes que recebem tratamentos diários e de até $47 \%$ em pacientes ambulatoriais.

No que se refere ao gênero, também não houve concordância entre os estudos analisados. Alonso-Arbiol et al. (2002) afirmaram que a dependência emocional tende a ser mais acentuada na população feminina. Myers et al. (2007) também encontraram uma relação entre a dependência emocional e a timidez e os ciúmes nas mulheres. No entanto, Franco e Aragón (2008) constataram maior presença de ciúmes em homens, além de raiva, dor, temor e desconfiança. Já outros estudos não encontraram relação significativa entre gênero e dependência (Jaller Jaramillo \& Lemos Hoyos, 2009; Lemos et al., 2012), impossibilitando extrair conclusões mais generalizadas sobre este tema.

Outro assunto estudado foi a violência. Os estudos afirmaram que indivíduos caracterizados como dependentes emocionais tem maiores chances de realizarem/sofrerem violência doméstica e ainda assim manterem-se no relacionamento (Bornstein, 2006; Charkow \& Nelson, 2000; Kane, Staiger, \& Ricciardelli, 2000). Além disto, apresentam maiores riscos de apresentar comportamentos autodestrutivos (Bornstein, 2012), doenças físicas e outras psicopatologias, como transtornos alimentares, transtornos ansiosos e somatizações (Arntz, 2005; Bornstein, 2012).

Com relação ao perfil cognitivo, os estudos divergiram. Lemos Hoyos et al. (2007) encontraram que os dependentes emocionais possuíam crenças centrais de dependência e paranoia, distorção cognitiva de falácia de mudança e um déficit na estratégia de enfrentamento autonomia. O esquema inicial desadaptativo predominante foi o de desconfiança/abuso (Lemos et al., 2012; Jaller Jaramillo \& Lemos Hoyos, 2009). Já no estudo de Lemos Hoyos et al. 
(2007), a distorção cognitiva que mais diferenciava os dependentes emocionais da população geral eram a falácia de controle e as "deverias".

Ainda sobre o perfil dos dependentes emocionais, observaram-se comportamentos de submissão ao outro, sinais de fissura e abstinência na ausência do objeto amado, ausência de decisões nos relacionamentos, sentimentos de insatisfação, vazio emocional, medo da solidão, baixa tolerância a frustração, tédio, desejo de autodestruição e sentimentos negativos, falta de consciência sobre seus problemas, sensação de estarem presos ao relacionamento e de que não conseguirão deixá-lo, conflitos de identidade, foco excessivo no outro e autonegligência, assunção de toda a responsabilidade pelos acontecimentos e necessidade de ajudar o parceiro, tentando resolver todos os problemas (Moral \& Sirvent, 2009). Sophia et al. (2009) também encontraram que os pacientes diagnosticados com dependência emocional eram mais impulsivos, apresentavam traços de evitação a danos, autotranscendência e possuíam relações mais insatisfatórias, quando comparados com um grupo controle. Já Bornstein e Cecero (2000) e Rubinstein (2007) observaram a presença de alguns traços de personalidade relacionados à dependência emocional, como neuroticismo e amabilidade.

Para o tratamento da Dependência Emocional, a psicoterapia individual é a mais indicada por todos os autores, que divergem com relação à sua abordagem. Sussman (2010) não menciona um marco teórico específico, mas cita a entrevista motivacional e o autogerenciamento como meios eficientes para lidar com a dependência emocional. Outros autores recomendam a realização de terapia da realidade (Hoogstad, 2008) e terapia comportamental ou de aceitação e compromisso (Izquierdo Martínez \& Gomes-Acosta, 2013). Outros tratamentos citados são a participação em grupos de apoio, especialmente aqueles com o programa dos doze passos, livros de autoajuda e terapia grupal (Sussman, 2010).

\section{DISCUSSÃO}

A dependência emocional é um tema que recebe vasta atenção popular, sendo tema de livros, filmes e programas de televisão. Recentemente, esta temática também vem ganhando espaço no campo científico, dada a sua alta incidência na população, variando entre 5\% a 24,5\% (Ahmdi et al., 2013; Gude et al., 2004; Jaller Jaramillo \& Lemos Hoyos, 2009; Lemos et al., 2012; Sussman, 2010). Entretanto, apesar das altas taxas de incidência e do número crescente de pesquisas na área, o tema ainda parece ser pouco estudado (Gude et al., 2004).

No presente estudo, foi encontrada uma multiplicidade de terminologias referentes a este transtorno, o que ilustra a confusão conceitual e nominal acerca da dependência emocional. Tal confusão é evidenciada pela falta de 
pesquisas na área e o escasso conhecimento sobre o assunto. Talvez pela falta de parâmetros funcionais fornecidos pela quarta edição do Manual Diagnóstico e Estatístico de Transtornos Mentais (DSM-IV) sobre o Transtorno de Personalidade Dependente, os pesquisadores passaram a utilizar outras nomenclaturas para o mesmo problema (Bornstein, 2006). Por exemplo, Arntz (2005) e Bornstein (2012) argumentaram que a definição do Transtorno de Personalidade Dependente fornecida pelo DSM-IV considerava apenas a dependência funcional e não contemplava traços de dependência emocional.

O DSM-5, apesar de incluir o Transtorno de Personalidade Dependente (TPD), sugere a sua retirada. No entanto, Bornstein (2011) questiona os métodos de formulação dos critérios diagnósticos do DSM, como: (a) informações imprecisas por parte do grupo dos consultores do DSM com relação à literatura utilizada para embasar as mudanças realizadas, não fornecendo dados sobre os critérios de inclusão e exclusão e o método utilizado para a revisão; (b) falta de suporte empírico para as mudanças propostas, pois, os estudos revisados não forneciam evidências suficientes de que os Transtornos de Personalidade que continuaram no manual possuíam mais validade e utilidade clínica do que aqueles que foram retirados. Por exemplo; encontrou-se que os custos de saúde associados com o Transtorno De Personalidade Histriônica e o Transtorno de Personalidade Dependente (recomendados para serem excluídos) foram maiores do que os custos associados aos Transtornos de Personalidade: obsessivo compulsivo, antissocial e esquiva (recomendados para continuarem no manual), sinalizando que o TPD traz sérios prejuízos psicossociais; (c) priorização de alguns transtornos de personalidade em detrimento de outros, visto que alguns transtornos foram mais estudados e, assim, possuíam mais evidências do que outros que não foram investigados. Portanto, é provável que, futuramente, o TPD receba uma nova e melhor categorização, uma vez que as adições comportamentais já estão sendo reconhecidas e incluídas no DSM como parte dos transtornos aditivos. Porém, ainda é necessário que se obtenha um melhor entendimento sobre as características desta dependência.

O perfil dos dependentes emocionais encontrado nos estudos revisados nesta pesquisa assemelha-se ao afirmado na literatura. De modo geral, as pessoas que tem dependência emocional são descritas como submissas, com dificuldades de tomar decisões em seus relacionamentos, sentindo-se responsáveis por todos os acontecimentos e centrando-se completamente em sua relação. Assim, tendem a prestar cuidados excessivos ao outro e resolver os seus problemas, mesmo que isso implique em se auto negligenciar (Moral \& Sirvent, 2008).

Não se encontrou um consenso nas pesquisas no que se refere à prevalência de gênero neste transtorno. Uma possível explicação para essa questão seria o fator cultural, uma vez que em algumas culturas se acredita que para as mulheres um relacionamento é essencial para a felicidade, e que elas 
devem ser submissas aos seus maridos, satisfazendo todos os seus desejos (Charkow \& Nelson, 2000). Além disto, o modo como as relações amorosas são retratadas na mídia e na literatura também acabam por reforçar os padrões patológicos da dependência emocional (Norwood, 1985; Sussman, 2010). Dessa forma, os fatores culturais, muitas vezes, levam os indivíduos a almejar relacionamentos dependentes, ou então, quando os vivem, acreditam que esta dependência seja "normal".

Apesar desta grande influência cultural no desenvolvimento e manutenção do transtorno, os estudos revisados mostraram que a dependência emocional deve ser entendida como um transtorno multifatorial, sendo influenciada também por fatores neurológicos e psicológicos. Pesquisas recentes têm investigado sobre as bases neurológicas do amor, encontrando que estas se assemelham aos mecanismos envolvidos na utilização de substâncias psicoativas (Fisher et al., 2005; Vasconcelos et al., 2002). Por outro lado, a vivência familiar e os estilos de apego aprendidos também contribuem com a dependência emocional (Feeney \& Noller, 1990; Hazan \& Shaver, 1987). Izquierdo Martinez e Gomes-Acosta (2013) e Sussman (2010) afirmam que os estilos de apego aprendidos durante a infância seriam repetidos na idade adulta, sendo predominante na dependência emocional o apego preocupado (Alonso-Arbiol et al., 2002; Franco \& Aragón, 2008) e o apego ambivalente (Ahmadi et al. 2013, Sophia et al. 2009). Em ambos, é predominante a visão negativa de si mesmo e a positiva de outros (Bartholomew \& Horowitz, 1991; Bartholomew \& Shaver, 1998). Indivíduos com estes padrões de apego apresentam maiores índices de culpa em situações de rejeição social, e cuidados e envolvimento excessivo com o outro (Bartholomew \& Horowitz, 1991). Assim, uma disfunção nos mecanismos neurais ou a sua junção com outros fatores, como o ambiente familiar, os estilos de apego e a cultura poderiam levar o indivíduo a estabelecer relações patológicas.

Os comportamentos autodestrutivos e as comorbidades também parecem fazer parte do quadro de dependência. Deste modo, a dependência emocional pode estar associada a transtornos alimentares, transtornos ansiosos, somatizações e depressão (Arntz, 2005; Bornstein, 2012). Além disso, aumentam as chances de o indivíduo cometer suicídio ou para-suicídio, que ocorreriam na tentativa de impedir o abandono por parte do parceiro, mostrando sua vulnerabilidade, impulsividade e baixa tolerância à frustração, características próprias dos dependentes emocionais (Bornstein, 2012).

Neste sentido, um tema bastante comum encontrado nos artigos analisados foi a violência. A dependência emocional seria um dos fatores de risco para a violência, principalmente a doméstica (Bornstein, 2006, 2012; Charkow \& Nelson, 2000; Kane et al., 2000). Aparentemente, homens que são emocionalmente dependentes de suas parceiras tendem a desempenhar mais frequentemente o papel de abusadores, enquanto que as mulheres dependentes 
tendem a ser vítimas (Bornstein, 2006, 2012). O dependente emocional tende a ser possessivo e tem medo de ser abandonado (Moral \& Sirvent, 2009), além de ser mais impulsivo (Sophia et al., 2009) e ciumento (Franco \& Aragón, 2008). Portanto, no caso dos homens, ao perceberem algum perigo em sua relação, seja ele real ou imaginário, podem tornar-se violentos e abusar de suas parceiras. No caso das mulheres, que geralmente são apontadas como vítimas, a dificuldade de término de relacionamento ocorre pelo medo de ficar sozinha e pelo sentimento de estar atada à relação (Moral \& Sirvent, 2009). Porém, é importante interpretar esses dados com cautela, uma vez que Bornstein, (2006) ressalta o fato de que todos os estudos na área investigam sempre homens como abusadores e mulheres como vítimas e não o inverso. Também é importante lembrar o caráter de adição da dependência emocional, o que torna ainda mais difícil romper o relacionamento, principalmente pelos sintomas de fissura e abstinência que acometem o indivíduo ao tentar sair da relação (Izquierdo Martínez \& Gomes-Acosta, 2013; Sussman, 2010).

Para entender a dinâmica dos relacionamentos dependentes e a frequente violência neles presente, faz-se importante citar o triangulo de Karpman (citado por Hoogstad, 2008), que tem em seus vértices os seguintes papéis: perseguidor, salvador e vítima. Assim, em relacionamentos nos quais impera a dependência emocional, cada indivíduo assume um papel e, por vezes, os parceiros trocam de papéis. Este modelo evidencia o problema de colocar papéis estáticos no âmbito da violência doméstica, com o homem como abusador e a mulher como vítima, uma vez que um relacionamento é algo dinâmico.

Também se nota a falta de estudos sobre os parceiros escolhidos pelos dependentes emocionais, já que a maioria dos estudos foca no dependente e não nos tipos de parceiros selecionados. O mais provável, segundo Moral e Sirvent (2008), é que ocorra uma dependência mútua, uma vez que os relacionamentos estabelecidos por estes tipos de indivíduos são extremamente conturbados, devido aos sentimentos de posse predominantes nos dependentes emocionais. Deste modo, a dependência mútua explicaria a permanência do parceiro e da relação, mesmo que conflituosa.

Portanto, devido a todas as implicações individuais e sociais relacionadas à dependência emocional, é importante analisar formas de prevenção e tratamento adequadas. São comuns os tratamentos em grupos de apoio, sendo que no Brasil podem-se encontrar grupos como o MADA (Mulheres que Amam Demais Anônimas) e os HADA ou HADES (Homens que Amam Demais Anônimos). No entanto, não foram encontradas pesquisas científicas sobre formas de intervenção ou prevenção dirigidas à dependência emocional, apesar de serem essenciais na discussão sobre qualquer psicopatologia. O fato da literatura específica indicar como um dos meios de tratamento livros de autoajuda (Sussman, 2010) e a disseminação dos grupos de apoio atesta que a literatura popular trata do assunto há mais tempo do que a científica e evidencia 
a pouca atenção dada pela Psicologia e Psiquiatria ao tema, visto que ainda não estabeleceram protocolos terapêuticos específicos para estes indivíduos.

Uma das dificuldades em tratar indivíduos com dependência emocional está relacionada à falta de consciência do problema por parte da população e dos próprios profissionais de saúde. Assim, o indivíduo tende a procurar psicoterapia quando um relacionamento chega ao seu fim e com a finalidade de mudar sua conduta de modo a poder reatar a relação perdida (Norwood, 1985; Sirvent, 2000). Por outro lado, quando este paciente busca ajuda de outros profissionais, a queixa é normalmente negligenciada ou amenizada, já que estes entendem que a dependência faz parte de qualquer relacionamento afetivo (Cogswell, Alloy, Karpinski, \& Grant, 2010).

Por fim, pode-se concluir sobre a necessidade de uma maior quantidade de estudos sobre o tema a fim de compreender algumas lacunas ainda existentes na literatura como: a escolha do parceiro, sua prevenção e tratamento, sua etiologia e prevalência, além de uma definição clara sobre os critérios diagnósticos. Apesar da discussão sobre a exclusão da dependência emocional dos manuais diagnósticos, este transtorno se mostra digno de atenção tanto devido à sua alta incidência na população como às suas consequências.

\section{CONSIDERAÇÕES FINAIS}

Neste estudo procurou-se revisar a produção científica acerca do tema da dependência emocional. Os resultados apontaram que este transtorno é caracterizado pela necessidade de estar em um relacionamento a fim de se atingir estabilidade emocional. Tal patologia se assemelha à dependência de substâncias, tanto em relação à sintomatologia quanto aos processos neurais envolvidos. Também foi observado que a dependência emocional pode ter sérias implicações tanto para quem sofre desta problemática como para aqueles que estão à sua volta, sendo a violência doméstica a consequência mais discutida.

Em função destas consequências negativas e do número de pessoas que sofrem dessa dependência, defende-se a necessidade de se obter uma visão mais precisa do tema. Apesar da alta incidência na população e do crescente número de publicações, o assunto ainda é negligenciado. Deste modo, acreditase que uma compreensão mais aprofundada do tema facilitará seu diagnóstico, prevenção e tratamento, aspectos ainda pouco estudados na área.

Foram encontradas algumas contradições na literatura específica, o que pode ser atribuído ao fato de ser um campo bastante influenciado por fatores culturais. Outra dificuldade encontrada foi a multiplicidade de terminologias utilizadas. Essa variedade dificulta o estudo do problema, impossibilitando a sintetização dos achados científicos já que, muitas vezes, os dados não são comparados justamente pela utilização de nomes diferentes. Assim, este estudo também se configurou como uma primeira tentativa de apresentar as diferenças 
entre as terminologias utilizadas, buscando uma compreensão mais abrangente deste transtorno.

É importante ressaltar algumas limitações do presente estudo, uma vez que, apesar da escolha cuidadosa dos descritores utilizados, alguns artigos provavelmente não foram encontrados devido à diversidade de nomenclaturas. Durante o desenvolvimento do trabalho, também foi notado que outras palavraschave pertinentes ao assunto não foram incluídas, como "Relationship dependency" e "Romance addiction". Essa limitação pode ser resolvida através da integração entre o presente estudo e futuras revisões de literatura que abordem tais descritores. A pouca acurácia de alguns artigos ao descrever seus resultados também impede uma conclusão mais precisa e unificada dos achados sobre o tema.

Portanto, acredita-se que este é um campo ainda pouco explorado, possibilitando que muitos estudos ainda sejam realizados. Apesar do número de publicações ser crescente, ainda são poucas as pesquisas que se dedicam a estudar este tema. Neste contexto, são necessários esclarecimentos sobre algumas questões, como a prevalência da dependência emocional tanto na população geral, quanto em relação a gêneros, verificando também a influência da cultura na incidência e manutenção desta patologia. Também é importante compreender melhor a dinâmica existente no relacionamento estabelecido por indivíduos dependentes e o tipo de parceiro escolhido por estas pessoas. Apesar de vários artigos teóricos versarem sobre a etiologia dessa dependência, não foi encontrada nenhuma pesquisa empírica sobre o assunto, o que é de extrema importância para o entendimento deste transtorno. Programas de tratamentos adequados para esse tipo específico de dependência também podem ser alvo de futuras pesquisas, já que muitos dos tratamentos sugeridos provêm de livros de autoajuda, derivam de tratamentos com dependentes químicos ou de tratamentos gerais adaptados para a dependência emocional. Tais intervenções geralmente não possuem testagem científica e nem comprovação de sua eficácia para pacientes com dependência emocional. Desta forma, faz-se necessário aumentar o debate sobre o tema a partir de pesquisas com maior rigor metodológico, de modo a ampliar a compreensão dos profissionais da saúde sobre a dependência emocional, seus aspectos constituintes e possibilidades de intervenção.

\section{REFERÊNCIAS}

As referências marcadas com o símbolo * fazem parte da revisão da literatura.

*Ahmadi, V., Davoudi, I., Ghazaei, M., \& Mardani, M. (2013). Prevalence of Obsessive Love and Its Association with Attachment Styles. Procedia-Social and Behavioral Sciences, 84, 696-700. doi:10.1016/j.sbspro.2013.06.629 
*Alonso-Arbiol, I., Shaver, P. R., \& Yárnoz, S. (2002). Insecure attachment, gender roles, and interpersonal dependency in the Basque Country. Personal Reationships, 9(4), 479-490. doi: 10.1111/1475-6811.00030

*Arntz, A. (2005). Pathological dependency: Distinguishing functional from emotional dependency. Clinical Psychology: Science and Practice, 12(4), 411-416. doi: 10.1093/clipsy.bpi051

Bartholomew, K., \& Horowitz, L. M. (1991). Attachment styles among young adults: a test of a four-category model. Journal of Personality and Social Psychology, 61(2), 226-224. doi: 10.1037/0022-3514.61.2.226

Bartholomew, K., \& Shaver, P. R. (1998). Methods of assessing adult attachment. In J. A. Simpson \& W. S. Rholes (Eds.), Attachment theory and close relationships, (pp. 25-45). New York: Guilford Press.

*Bornstein, R. F. (2006). The complex relationship between dependency and domestic violence: converging psychological factors and social forces. American Psychologist, 61(6), 595-606. doi: 10.1037/0003-066X.61.6.595

Bornstein, R. F. (2011). Reconceptualizing personality pathology in DSM-5: Limitations in evidence for eliminating dependent personality disorder and other DSM-IV syndromes. Journal of Personality Disorders, 25(2), 235-247. doi: 10.1521/pedi.2011.25.2.235

*Bornstein, R. F. (2012). Illuminating a neglected clinical issue: Societal costs of interpersonal dependency and dependent personality disorder. Journal of clinical psychology, 68(7), 766-781. doi: 10.1002/jclp.21870

*Bornstein, R. F., \& Cecero, J. J. (2000). Deconstructing dependency in a fivefactor world: A meta-analytic review. Journal of Personality Assessment, 74(2), 324-343. doi: 10.1207/S15327752JPA7402_11

*Charkow, W. B., \& Nelson, E. S. (2000). Relationship dependency, dating violence, and scripts of female college students. Journal of College Counseling, 3(1), 17-28. doi: 10.1002/j.2161-1882.2000.tb00160.x

Cogswell, A., Alloy, L. B., Karpinski, A., \& Grant, D. A. (2010). Assessing dependency using self-report and indirect measures: Examining the significance of discrepancies. Journal of Personality Assessment, 92(4), 306-316. doi: 10.1080/00223891.2010.481986

Fisher, H., Aron, A., \& Brown, L. L. (2005). Romantic love: An fMRI study of a neural mechanism for mate choice. Journal of Comparative Neurology, 493 (1), 58-62. doi: 10.1002/cne.20772

Feeney, J. A., \& Noller, P. (1990). Attachment style as a predictor of adult romantic relationships. Journal of Personality and Social Psychology, 58(2), 281-291.

*Franco, B. E. R., \& Aragón, R. S. (2008). El Papel de los Estilos de Apego y los Celos en la Asociación con el Amor Adictivo. Psicología, 16(1), 15-22. 
*Gude, T., Hoffart, A., Hedley, L., \& Rø, Ø. (2004). The dimensionality of dependent personality disorder. Journal of Personality Disorders, 18(6), 604-610. doi: 10.1521/pedi.18.6.604.54793

Hazan, C., \& Shaver, P. (1987). Romantic love conceptualized as an attachment process. Journal of Personality and Social Psychology, 52(3), 511-524. doi: $10.1037 / 0022-3514.52 .3 .511$

*Hoogstad, J. (2008). Choice Theory and Emotional Dependency. International Journal of Reality Therapy, 28(1), 63-68.

*Izquierdo Martínez, S. A., \& Gómez-Acosta, A. (2013). Dependencia afectiva: abordaje desde una perspectiva contextual. Psychologia: Avances De La Disciplina, 7(1), 81-91.

*Jaller Jaramillo, C., \& Lemos Hoyos, M. (2009). Esquemas desadaptivos tempranos en estudiantes universitarios con dependencia emocional. Acta Colombiana de Psicología, 12(2), 77-83.

*Kane, T. A., Staiger, P. K., \& Ricciardelli, L. A. (2000). Male domestic violence attitudes, aggression, and interpersonal dependency. Journal of Interpersonal Violence, 15(1), 16-29. doi: 10.1177/088626000015001002

*Lemos Hoyos, M., Londoño Arredondo, N. H., \& Zapata Echavarría, J. A. (2007). Distorsiones cognitivas en personas con dependencia emocional. Informes Psicológicos, 9(9), 55-69.

*Lemos, M., Jaller, C., González, M. A., Díaz, Z. T., \& De La Ossa, D. (2012). Perfil cognitivo de la dependencia emocional en estudiantes universitarios en Medellín, Colombia. Universitas Psychologica, 11(2), 395-404.

Moral, M. V., \& Sirvent, C. (2008). Dependencias sentimentales o afectivas: Etiología clasificación y evaluación. Revista Española de Drogodependencias, 33(2), 151-167.

*Moral, M. V., \& Sirvent, C. (2009). Dependencia afectiva y género: Perfil sintomático diferencial en dependientes afectivos españoles. Interamerican Journal of Psychology, 43(2), 230-240.

*Myers, B., Dilks, L. S., \& Marceaux, J. (2007). An Exploration of Shyness and its Relationship to Partner Dependency in Romantic Relationships. North American Journal of Psychology, 9(2), 293-302.

Norwood, R. (1985). Women who love too much: When you keep wishing and hoping he'll change. New York, NY: Simon and Schuster.

*Rubinstein, G. (2007). Two behavioral indicators of dependency and the Five-Factor Model of personality. Psychology and Psychotherapy: Theory, Research and Practice, 80(3), 333-342. doi: 10.1348/147608306X133576

Sánchez Aragón, R. (2007). Significado psicológico del amor pasional: Lo claro y lo obscuro. Interamerican Journal of Psychology, 41(3), 391-402. 
Sirvent, C. (2000, octubre). Las dependencias relacionales (D.R.): Dependencia emocional, codependencia y bidependencia. Resumos de Ponencias y Comunicaciones I Symposium Nacional sobre Adicción en la Mujer, Madrid, Espanha, 27-30. Disponível em http://www.fispiral.com.es/images/06PDFs/libros/I-symposium.pdf

*Sophia, E. C., Tavares, H., Berti, M. P., Pereira, A. P., Lorena, A., Mello, C., ..., \& Ziilberman, M. L. (2009). Pathological love: Impulsivity, personality, and romantic relationship. CNS spectrums, 14(5), 268-274.

Sternberg, R. J. (1988). The triangle of love: Intimacy, passion, commitment. New York, NY: Basic Books.

*Sussman, S. (2010). Love addiction: Definition, etiology, treatment. Sexual Addiction \& Compulsivity, 17(1), 31-45. doi: 10.1080/10720161003604095

Vasconcelos, S. M., Feitosa, L. B., Felix, P. A., Aguiar, L. M. V., de Sousa, F. C. F., \& Viana, G. S. B. (2002). Motivação, vias neuronais e drogas de abuso. Revista Psiquiatria Clínica, 29(3), 130-134.

Yela, C. (1997). Curso temporal de los componentes básicos del amor a lo largo de la relación de pareja. Psicothema, 9(1), 1-15.

Sobre as autoras

Denise Catricala Bution é psicóloga e pesquisadora no GREA (Grupo de Estudos Interdisciplinar em álcool e outras drogas) - Instituto de Psiquiatria do Hospital das Clínicas da FMUSP. E-mail: dbution@gmail.com Amanda Muglia Wechsler é psicóloga, mestre em Psicologia e doutora em Psicologia da Saúde pela Universidad Complutense de Madrid. É professora do Centro Universitário UNIFAFIBE. E-mail: amanda_wechsler@yahoo.com.br

Recebido em: 19/11/2015 1 a revisão em: 08/03/2016 $2^{a}$ revisão em: 19/03/2016

Aceito em: 29/03/2016 
Apêndice A. Resumo geral dos artigos revisados.

\begin{tabular}{|c|c|c|c|c|}
\hline Autor & Participantes & Objetivo & Medidas & Resultados \\
\hline $\begin{array}{l}\text { Ahmadi } \\
\text { et al. } \\
(2013)\end{array}$ & $\begin{array}{l}290 \\
\text { estudantes } \\
\text { de } \\
\text { graduação: } \\
117 \\
\text { mulheres e } \\
173 \\
\text { homens. }\end{array}$ & $\begin{array}{l}\text { Verificar a } \\
\text { existência } \\
\text { de amor } \\
\text { obsessivo e } \\
\text { sua relação } \\
\text { com os } \\
\text { estilos de } \\
\text { apego. }\end{array}$ & $\begin{array}{l}\text { - Passionate } \\
\text { Love Scale } \\
\text { (PLS); } \\
\text { - Adult } \\
\text { Attachment } \\
\text { Inventory; }\end{array}$ & $\begin{array}{l}\text {-A prevalência de } \\
\text { amor obsessivo na } \\
\text { amostra foi de } \\
17,9 \% \text {; } \\
\text {-Correlação } \\
\text { significativa e } \\
\text { positiva entre amor } \\
\text { obsessivo e apego } \\
\text { ambivalente. }\end{array}$ \\
\hline $\begin{array}{l}\text { Alonso- } \\
\text { Arbiol et } \\
\text { al. } \\
(2002)\end{array}$ & $\begin{array}{l}602 \\
\text { estudantes } \\
\text { de } \\
\text { graduação: } \\
291 \\
\text { mulheres e } \\
311 \\
\text { homens. }\end{array}$ & $\begin{array}{l}\text { Verificar a } \\
\text { relação } \\
\text { entre } \\
\text { gênero, } \\
\text { dependência } \\
\text { instrumental } \\
\text { e emocional, } \\
\text { identidade } \\
\text { de gênero e } \\
\text { apego. }\end{array}$ & $\begin{array}{l}\text {-Emotional } \\
\text { Reliance on } \\
\text { Another Person } \\
\text { and Lack of } \\
\text { Social Self- } \\
\text { Confidence } \\
\text { subscales } \\
\text { (subscale of the } \\
\text { Interpersonal } \\
\text { Dependency } \\
\text { Inventory); } \\
\text {-Bem Sex Role } \\
\text { Inventory } \\
\text { (BSRI); } \\
\text {-Experiences in } \\
\text { Close } \\
\text { Relationship } \\
\text { (ECR); } \\
\text {-Relationship } \\
\text { Questionnaire } \\
\text { (RQ). }\end{array}$ & $\begin{array}{l}\text {-Mulheres com } \\
\text { maior dependência } \\
\text { instrumental e } \\
\text { emocional; } \\
\text {-Correlação } \\
\text { significativa e } \\
\text { positiva entre } \\
\text { dependência } \\
\text { instrumental e } \\
\text { emocional com } \\
\text { ansiedade (relativa } \\
\text { ao apego) } \\
\text { - Correlação } \\
\text { significativa e } \\
\text { positiva entre } \\
\text { dependência } \\
\text { instrumental e } \\
\text { evasão (relativa ao } \\
\text { apego); } \\
\text {-Forte relação } \\
\text { positiva entre } \\
\text { dependência } \\
\text { emocional e apego } \\
\text { preocupado e } \\
\text { medroso; }\end{array}$ \\
\hline $\begin{array}{l}\text { Arntz } \\
\text { (2005) }\end{array}$ & $\begin{array}{l}\text { Não se } \\
\text { aplica }\end{array}$ & $\begin{array}{l}\text { Distinguir } \\
\text { dependência } \\
\text { funcional de } \\
\text { dependência } \\
\text { emocional. }\end{array}$ & Não se aplica & $\begin{array}{l}\text { - Dependência } \\
\text { funcional: } \\
\text { necessidade de } \\
\text { outra pessoa mais } \\
\text { forte e incapacidade } \\
\text { de cuidar de si } \\
\text { mesmo. } \\
\text { - Dependência } \\
\text { emocional: } \\
\text { necessidade de } \\
\text { envolvimento } \\
\text { emocional com outra } \\
\text { pessoa. }\end{array}$ \\
\hline
\end{tabular}




\begin{tabular}{|c|c|c|c|c|}
\hline Autor & Participantes & Objetivo & Medidas & Resultados \\
\hline $\begin{array}{l}\text { Bornstein } \\
(2006)\end{array}$ & Não se aplica & $\begin{array}{l}\text { Discutir a } \\
\text { relação entre } \\
\text { Dependência } \\
\text { Emocional e } \\
\text { Econômica e } \\
\text { a violência } \\
\text { doméstica. }\end{array}$ & Não se aplica. & $\begin{array}{l}\text { - Altos níveis de } \\
\text { dependência } \\
\text { econômica em } \\
\text { mulheres e altos } \\
\text { níveis de dependência } \\
\text { emocional em } \\
\text { homens aumentam as } \\
\text { chances de ocorrer } \\
\text { violência doméstica. }\end{array}$ \\
\hline $\begin{array}{l}\text { Bornstein } \\
\text { (2012) }\end{array}$ & $\begin{array}{l}\text { Não se } \\
\text { aplica. }\end{array}$ & $\begin{array}{l}\text { Relacionar } \\
\text { traços de } \\
\text { dependência } \\
\text { ou de } \\
\text { Transtorno } \\
\text { de } \\
\text { Personalidade } \\
\text { Dependente } \\
\text { com } \\
\text { comportamen } \\
\text { tos } \\
\text { destrutivos } \\
\text { ou } \\
\text { autodestrutiv } \\
\text { os. }\end{array}$ & Não se aplica. & $\begin{array}{l}\text {-Altos níveis de } \\
\text { dependência e } \\
\text { Transtorno de } \\
\text { Personalidade } \\
\text { Dependente estão } \\
\text { relacionados a um } \\
\text { maior risco de } \\
\text { doenças físicas, } \\
\text { violência doméstica, } \\
\text { suicídio, } \\
\text { comprometimento } \\
\text { funcional e aumento } \\
\text { nos gastos } \\
\text { relacionados à saúde. }\end{array}$ \\
\hline $\begin{array}{l}\text { Bornstein } \\
\text { e Cecero } \\
(2000)\end{array}$ & $\begin{array}{l}18 \text { artigos } \\
\text { científicos }\end{array}$ & $\begin{array}{l}\text { Relacionar } \\
\text { dependência } \\
\text { interpessoal } \\
\text { com os traços } \\
\text { do modelo } \\
\text { dos Cinco } \\
\text { Grandes } \\
\text { Fatores. }\end{array}$ & Não se aplica. & $\begin{array}{l}\text {-Correlação positiva e } \\
\text { significativa entre } \\
\text { dependência e } \\
\text { Neuroticismo e } \\
\text { Amabilidade; } \\
\text {-Correlação negativa } \\
\text { e significativa entre } \\
\text { dependência e } \\
\text { Extroversão, Abertura } \\
\text { e Conscienciosidade; }\end{array}$ \\
\hline $\begin{array}{l}\text { Charkow } \\
\text { e Nelson } \\
(2000)\end{array}$ & $\begin{array}{l}178 \\
\text { estudantes } \\
\text { de graduação } \\
\text { do sexo } \\
\text { feminino. }\end{array}$ & $\begin{array}{l}\text { Investigar a } \\
\text { relação entre } \\
\text { dependência, } \\
\text { violência e } \\
\text { papéis nos } \\
\text { relacionamen } \\
\text { tos } \\
\text { amorosos. }\end{array}$ & $\begin{array}{l}\text {-The Love } \\
\text { Relationships } \\
\text { Questionnaire } \\
\text { (LRQ); } \\
\text { - The Conflict } \\
\text { Tactics Scale } \\
\text { (CTS), a slightly } \\
\text { modified } \\
\text { version; } \\
\text {-13 Scenarios. }\end{array}$ & $\begin{array}{l}\text {-Correlação } \\
\text { significativa e positiva } \\
\text { entre dependência } \\
\text { nos relacionamentos } \\
\text { com presença de } \\
\text { violência física e } \\
\text { verbal e papéis } \\
\text { dependentes e } \\
\text { imaturos. }\end{array}$ \\
\hline
\end{tabular}




\begin{tabular}{|c|c|c|c|c|}
\hline Autor & Participantes & Objetivo & Medidas & Resultados \\
\hline $\begin{array}{l}\text { Franco e } \\
\text { Aragón } \\
(2008)\end{array}$ & $\begin{array}{l}176 \\
\text { participantes: } \\
88 \text { homens e } \\
88 \text { mulheres. }\end{array}$ & $\begin{array}{l}\text { Verificar a } \\
\text { relação } \\
\text { existente } \\
\text { entre os } \\
\text { estilos de } \\
\text { apego e } \\
\text { ciúmes com } \\
\text { dependência } \\
\text { amorosa. }\end{array}$ & $\begin{array}{l}\text {-Cartoons de } \\
\text { Estilos de Apego } \\
\text { (Viñetas de } \\
\text { Estilos de } \\
\text { Apego); } \\
\text {-Escala } \\
\text { Multidimensional } \\
\text { de Ciúme, } \\
\text { versão curta; } \\
\text {-Escala de } \\
\text { Dependencia } \\
\text { Amorosa (Escala } \\
\text { De Adicción Al } \\
\text { Amor). }\end{array}$ & $\begin{array}{l}\text {-Indivíduos com } \\
\text { apego preocupado ou } \\
\text { temeroso exibiram } \\
\text { mais medo, } \\
\text { desconfiança, raiva e } \\
\text { dor em sua relação } \\
\text { romântica; } \\
\text {-Sujeitos com apego } \\
\text { indiferente tendem a } \\
\text { sentir mais } \\
\text { desconfiança, ira, } \\
\text { medo/frustração; } \\
\text {-Participantes com } \\
\text { dependência amorosa } \\
\text { apresentaram apego } \\
\text { preocupado ou } \\
\text { indiferente e } \\
\text { obtiveram escores } \\
\text { mais altos em raiva, } \\
\text { dor, medo e } \\
\text { desconfiança; } \\
\text {-Homens obtiveram } \\
\text { coeficientes mais } \\
\text { altos de ciúmes; } \\
\text {-Dependência } \\
\text { amorosa com maior } \\
\text { relação com o apego } \\
\text { preocupado nas } \\
\text { mulheres; }\end{array}$ \\
\hline $\begin{array}{l}\text { Gude et } \\
\text { al. } \\
(2004)\end{array}$ & $\begin{array}{l}182 \\
\text { participantes } \\
\text { divididos em } \\
\text { três grupos: } \\
117 \text { com } \\
\text { agorafobia } \\
\text { subdivididos } \\
\text { em dois sub- } \\
\text { grupos, com } \\
\text { transtorno de } \\
\text { pânico ( } 91 \% \text { ) } \\
\text { e sem } \\
\text { transtorno do } \\
\text { pânico ( } 9 \% \text { ) } \\
\text { e } 65 \\
\text { pacientes } \\
\text { com } \\
\text { transtornos } \\
\text { alimentares. }\end{array}$ & $\begin{array}{l}\text { Relacionar o } \\
\text { modelo de } \\
\text { dois } \\
\text { componentes } \\
\text { proposto por } \\
\text { Livesley com } \\
\text { o critério de } \\
\text { Transtorno } \\
\text { de } \\
\text { Personalidade } \\
\text { dependente } \\
\text { do DSM-IV. }\end{array}$ & $\begin{array}{l}\text {-Structured } \\
\text { Clinical } \\
\text { Interview for } \\
\text { DSM-IV; } \\
\text {-Schema } \\
\text { Questionnaire; } \\
\text {-Beck } \\
\text { Depression } \\
\text { Inventory. }\end{array}$ & $\begin{array}{l}\text {-Correlação } \\
\text { significativa e positiva } \\
\text { entre o Esquema } \\
\text { Inicial Desadaptativo } \\
\text { "abandono/instabilida } \\
\text { de" e o índice } \\
\text { "apego/abandono" } \\
\text {-Correlação } \\
\text { significativa e positiva } \\
\text { entre o Esquema } \\
\text { Inicial Desadaptativo } \\
\text { "falha" e o índice } \\
\text { "dependência/ } \\
\text { incompetência". }\end{array}$ \\
\hline
\end{tabular}




\begin{tabular}{|c|c|c|c|c|}
\hline Autor & Participantes & Objetivo & Medidas & Resultados \\
\hline $\begin{array}{l}\text { Hoogstad } \\
(2008)\end{array}$ & $\begin{array}{l}\text { Não se } \\
\text { aplica. }\end{array}$ & $\begin{array}{l}\text { Conceituar a } \\
\text { dependência } \\
\text { emocional e } \\
\text { seu } \\
\text { desenvolvime } \\
\text { nto. }\end{array}$ & Não se aplica & $\begin{array}{l}\text {-Dependência } \\
\text { emocional: } \\
\text { estabilidade e } \\
\text { segurança emocional. } \\
\text {-Origem: infância, em } \\
\text { ambiente sem amor } \\
\text { e/ou aceitação } \\
\text { incondicional. }\end{array}$ \\
\hline $\begin{array}{l}\text { Izquierdo } \\
\text { Martínez } \\
\text { e Gomes- } \\
\text { Acosta } \\
\text { (2013) }\end{array}$ & Não se aplica & $\begin{array}{l}\text { Realizar uma } \\
\text { revisão } \\
\text { teórica sobre } \\
\text { dependência } \\
\text { emocional. }\end{array}$ & Não se aplica & $\begin{array}{l}\text {-Dependência } \\
\text { emocional: padrão de } \\
\text { comportamentos que } \\
\text { afeta diretamente as } \\
\text { relações } \\
\text { interpessoais, visando } \\
\text { preservá-las. } \\
\text { - Origem: apego } \\
\text { inadequado na } \\
\text { infância. } \\
\text { - Sugestões de } \\
\text { intervenções: uso de } \\
\text { reforço diferencial, } \\
\text { treinamento de } \\
\text { habilidades socia is, } \\
\text { exposição com } \\
\text { prevenção de } \\
\text { respostas, terapia de } \\
\text { aceitação e } \\
\text { compromisso e } \\
\text { terapia } \\
\text { comportamental de } \\
\text { casal. }\end{array}$ \\
\hline $\begin{array}{l}\text { Jaller } \\
\text { Jaramillo } \\
\text { e Lemos } \\
\text { Hoyos } \\
(2009)\end{array}$ & $\begin{array}{l}569 \\
\text { estudantes } \\
\text { universitários } \\
: 386 \\
\text { mulheres e } \\
183 \text { homens. }\end{array}$ & $\begin{array}{l}\text { Verificar os } \\
\text { esquemas } \\
\text { iniciais } \\
\text { desadaptativ } \\
\text { os } \\
\text { apresentados } \\
\text { por } \\
\text { indivíduos } \\
\text { com } \\
\text { dependência } \\
\text { emocional. }\end{array}$ & $\begin{array}{l}\text {-Questionário de } \\
\text { Dependência } \\
\text { Emocional } \\
\text { (Cuestionario de } \\
\text { Dependencia } \\
\text { Emocional - } \\
\text { CDE); } \\
\text { - Questionário } \\
\text { de Esquemas de } \\
\text { Young, forma } \\
\text { longa; }\end{array}$ & $\begin{array}{l}\text { - 24,6\% com } \\
\text { dependência } \\
\text { emocional; } \\
\text {-Sem relação } \\
\text { significativa entre } \\
\text { dependência } \\
\text { emocional e gênero; } \\
\text { - Esquemas iniciais } \\
\text { desadaptativos com } \\
\text { maior relação com a } \\
\text { dependência } \\
\text { emocional: } \\
\text { Autodisciplina/ } \\
\text { Autocontrole } \\
\text { Insuficientes e } \\
\text { Desconfiança/Abuso. }\end{array}$ \\
\hline
\end{tabular}




\begin{tabular}{|c|c|c|c|c|}
\hline Autor & Participantes & Objetivo & Medidas & Resultados \\
\hline $\begin{array}{l}\text { Kane et } \\
\text { al. }(2000)\end{array}$ & $\begin{array}{l}83 \text { homens: } \\
23 \\
\text { participantes } \\
\text { de um } \\
\text { programa de } \\
\text { intervenção } \\
\text { para homens } \\
\text { que haviam } \\
\text { praticado } \\
\text { violência } \\
\text { contra sua } \\
\text { parceira, } 30 \\
\text { jogadores de } \\
\text { futebol } \\
\text { americano e } \\
30 \text { homens } \\
\text { que } \\
\text { participavam } \\
\text { de trabalhos } \\
\text { voluntários. }\end{array}$ & $\begin{array}{l}\text { Comparar } \\
\text { crenças sobre } \\
\text { violência } \\
\text { doméstica, } \\
\text { agressão } \\
\text { geral e } \\
\text { dependência } \\
\text { interpessoal } \\
\text { nos três } \\
\text { grupos. }\end{array}$ & $\begin{array}{l}\text {-Brief Anger- } \\
\text { Agression } \\
\text { Questionnaire; } \\
\text { - Inventory of } \\
\text { Beliefs About } \\
\text { Wife Beating } \\
\text { (IBWB); } \\
\text { - Interpersonal } \\
\text { Dependency } \\
\text { Inventory; } \\
\text {-Demographic } \\
\text { Questionnaire. }\end{array}$ & $\begin{array}{l}\text {-Niveis } \\
\text { significativamente } \\
\text { maiores de } \\
\text { dependência } \\
\text { interpessoal e } \\
\text { violência em homens } \\
\text { do grupo de } \\
\text { intervenção; } \\
\text {-Homens do grupo de } \\
\text { intervenção } \\
\text { apresentaram altos } \\
\text { níveis de dependência } \\
\text { em relação às suas } \\
\text { parceiras; } \\
\text {-Em todos os grupos } \\
\text { foram encontradas } \\
\text { atitudes de oposição } \\
\text { ao uso de violência } \\
\text { doméstica. }\end{array}$ \\
\hline $\begin{array}{l}\text { Lemos et } \\
\text { al. (2012) }\end{array}$ & $\begin{array}{l}569 \\
\text { estudantes } \\
\text { universitários } \\
: 386 \\
\text { mulheres e } \\
183 \text { homens. }\end{array}$ & $\begin{array}{l}\text { Identificar o } \\
\text { perfil } \\
\text { cognitivo de } \\
\text { dependentes } \\
\text { emocionais. }\end{array}$ & $\begin{array}{l}\text {-Cuestionario de } \\
\text { Dependencia } \\
\text { Emocional - } \\
\text { CDE; } \\
\text { - Questionário } \\
\text { de Esquemas de } \\
\text { Young, forma } \\
\text { longa; } \\
\text {-Questionário de } \\
\text { Crenças Centrais } \\
\text { dos Transtornos } \\
\text { de Personalidade } \\
\text { (Cuestionario de } \\
\text { Creencias } \\
\text { Centrales de los } \\
\text { Trastornos de la } \\
\text { Personalidad - } \\
\text { CCE-TP); } \\
\text {-Inventário de } \\
\text { Pensamentos } \\
\text { Automáticos; } \\
\text {-Questionário de } \\
\text { Enfrentamento } \\
\text { de Lazarus e } \\
\text { Folkman } \\
\text { Modificado. }\end{array}$ & $\begin{array}{l}\text { - } 24,6 \% \\
\text { apresentaram } \\
\text { dependência } \\
\text { emocional; } \\
\text {-Sem relação } \\
\text { significativa entre } \\
\text { dependência } \\
\text { emocional e gênero; } \\
\text {-Perfil cognitivo dos } \\
\text { dependentes } \\
\text { emocionais } \\
\text { caracterizado por: } \\
\text { Esquema Inicial } \\
\text { Dasadaptativo } \\
\text { "Desconfiança/Abuso" } \\
\text { crenças centrais } \\
\text { "dependentes" e } \\
\text { "paranoides", } \\
\text { distorção cognitiva de } \\
\text { "falácia de mudança" } \\
\text { e estratégia de } \\
\text { enfrentamento (com } \\
\text { coeficiente negativo) } \\
\text { de "autonomia". }\end{array}$ \\
\hline
\end{tabular}




\begin{tabular}{|c|c|c|c|c|}
\hline Autor & Participantes & Objetivo & Medidas & Resultados \\
\hline $\begin{array}{l}\text { Lemos } \\
\text { Hoyos et } \\
\text { al. (2007) }\end{array}$ & $\begin{array}{l}116 \\
\text { participantes: } \\
22 \text { com } \\
\text { dependência } \\
\text { emocional e } \\
94 \text { sem } \\
\text { dependência } \\
\text { emocional. }\end{array}$ & $\begin{array}{l}\text { Definir as } \\
\text { distorções } \\
\text { cognitivas } \\
\text { apresentadas } \\
\text { por } \\
\text { indivíduos } \\
\text { com } \\
\text { Dependência } \\
\text { Emocional. }\end{array}$ & $\begin{array}{l}\text {-Questionário de } \\
\text { Dependência } \\
\text { Emocional } \\
\text { (Cuestionário de } \\
\text { Dependencia } \\
\text { Emocional - } \\
\text { CDE); } \\
\text {-Inventário de } \\
\text { Pensamentos } \\
\text { Automáticos } \\
\text { (Inventario de } \\
\text { Pensamientos } \\
\text { Automáticos } \\
\text { IPA). }\end{array}$ & $\begin{array}{l}\text {-Diferença } \\
\text { significativa entre } \\
\text { sujeitos com } \\
\text { dependência } \\
\text { emocional e grupo } \\
\text { controle em } 12 \text { das } \\
15 \text { distorções } \\
\text { cognitivas avaliadas, } \\
\text { sendo elas: Abstração } \\
\text { Seletiva, Pensamento } \\
\text { Dicotômico, } \\
\text { Supergeneralização, } \\
\text { Inferência Arbitrária, } \\
\text { Catastrofização, } \\
\text { Falácia de Controle, } \\
\text { Falácia de Justiça, } \\
\text { Raciocínio Emocional, } \\
\text { Falácia de Mudança, } \\
\text { Deveria, Falácia de } \\
\text { Razão e Recompensa } \\
\text { Divina. } \\
\text {-Falácia de Controle e } \\
\text { Deveria foram as que } \\
\text { mais diferenciavam os } \\
\text { dependentes dos } \\
\text { sujeitos no grupo } \\
\text { controle. }\end{array}$ \\
\hline $\begin{array}{l}\text { Moral e } \\
\text { Sirvent } \\
\text { (2009) }\end{array}$ & $\begin{array}{l}78 \\
\text { participantes } \\
\text { diagnosticado } \\
\text { s como } \\
\text { dependentes } \\
\text { emocionais e } \\
\text { um grupo } \\
\text { controle } \\
\text { composto por } \\
311 \text { pessoas } \\
\text { selecionadas } \\
\text { aleatoriamen } \\
\text { te. }\end{array}$ & $\begin{array}{l}\text { Traçar um } \\
\text { perfil } \\
\text { diferencial } \\
\text { entre } \\
\text { dependentes } \\
\text { emocionais e } \\
\text { a população } \\
\text { geral. }\end{array}$ & $\begin{array}{l}\text { - Teste de } \\
\text { Dependências } \\
\text { Sentimentais - } \\
100 \text { (Test de } \\
\text { Dependencias } \\
\text { Sentimentales- } \\
100 \text { - TDS-100); }\end{array}$ & $\begin{array}{l}\text {-Dependentes } \\
\text { emocionais se } \\
\text { submetem ao outro, } \\
\text { são possessivos, } \\
\text { apresentam sinais de } \\
\text { fissura (craving) e } \\
\text { abstinência, } \\
\text { sentimentos } \\
\text { negativos como culpa, } \\
\text { vazio emocional e } \\
\text { medo de ser } \\
\text { abandonado, } \\
\text { inevitabilidade } \\
\text { emocional, conflitos } \\
\text { de identidade e } \\
\text { utilizam lócus de } \\
\text { controle externo; } \\
\text {-Diferença } \\
\text { significativa entre os } \\
\text { dependentes } \\
\text { emocionais e o grupo } \\
\text { controle em todos os } \\
\text { vinte e três fatores } \\
\text { explorados pelo TDS- } \\
\text { 100; }\end{array}$ \\
\hline
\end{tabular}




\begin{tabular}{|c|c|c|c|c|}
\hline Autor & Participantes & Objetivo & Medidas & Resultados \\
\hline $\begin{array}{l}\text { Myers et } \\
\text { al. (2007) }\end{array}$ & $\begin{array}{l}107 \\
\text { estudantes } \\
\text { de Psicologia: } \\
30 \text { homens e } \\
77 \text { mulheres. }\end{array}$ & $\begin{array}{l}\text { Explorar a } \\
\text { relação entre } \\
\text { timidez e } \\
\text { dependência } \\
\text { interpessoal. }\end{array}$ & $\begin{array}{l}\text { - Shyness Scale; } \\
\text { - Spouse- } \\
\text { Specific } \\
\text { Dependecy } \\
\text { Scale. }\end{array}$ & $\begin{array}{l}\text {-Sem relação } \\
\text { significativa entre } \\
\text { timidez e apego } \\
\text { ansioso; } \\
\text {-Correlação positiva e } \\
\text { significativa em } \\
\text { mulheres entre } \\
\text { timidez e dependência } \\
\text { exclusiva, entre } \\
\text { timidez e dependência } \\
\text { emocional e entre } \\
\text { timidez e dependência } \\
\text { geral. }\end{array}$ \\
\hline $\begin{array}{l}\text { Rubinstei } \\
\text { n (2007) }\end{array}$ & $\begin{array}{l}601 \\
\text { estudantes } \\
\text { de } \\
\text { graduação: } \\
287 \text { homens } \\
\text { e } 314 \\
\text { mulheres. }\end{array}$ & $\begin{array}{l}\text { Relacionar } \\
\text { comportamen } \\
\text { tos que } \\
\text { indiquem } \\
\text { dependência } \\
\text { com os traços } \\
\text { do Modelo } \\
\text { dos Cinco } \\
\text { Grandes } \\
\text { Fatores. }\end{array}$ & $\begin{array}{l}\text { - Demographic } \\
\text { Questionnaire; } \\
\text {-NEO-FFI; } \\
\text {-Dependent } \\
\text { Personality } \\
\text { Dirsorder (DPD): } \\
\text { Typical beliefs. }\end{array}$ & $\begin{array}{l}\text {-Relação negativa e } \\
\text { significativa de } \\
\text { dependência com } \\
\text { abertura, } \\
\text { conscienciosidade e } \\
\text { extroversão. } \\
\text { - Relação negativa e } \\
\text { significativa de idade } \\
\text { com dependência e } \\
\text { idade com } \\
\text { neuroticismo } \\
\text { - Relação negativa e } \\
\text { significativa de renda } \\
\text { individual com } \\
\text { dependência, } \\
\text { amabilidade e } \\
\text { neuroticismo } \\
\text { - Relação positiva e } \\
\text { significativa entre } \\
\text { dependência e } \\
\text { neuroticismo e } \\
\text { amabilidade } \\
\text { - Relação significativa } \\
\text { e positiva entre renda } \\
\text { e abertura e } \\
\text { extroversão; }\end{array}$ \\
\hline
\end{tabular}




\begin{tabular}{|c|c|c|c|c|}
\hline Autor & Participantes & Objetivo & Medidas & Resultados \\
\hline $\begin{array}{l}\text { Sophia et } \\
\text { al. (2009) }\end{array}$ & $\begin{array}{l}89 \\
\text { participantes: } \\
50 \\
\text { diagnosticada } \\
\text { s com Amor } \\
\text { Patológico e } \\
39 \text { indivíduos } \\
\text { sem } \\
\text { diagnóstico } \\
\text { de } \\
\text { psicopatologi } \\
\text { as. }\end{array}$ & $\begin{array}{l}\text { Comparar os } \\
\text { dois grupos } \\
\text { com relação } \\
\text { a: } \\
\text { impulsividade } \\
\text { ' personalidade } \\
\text { e satisfação } \\
\text { em } \\
\text { relacionamen } \\
\text { tos } \\
\text { românticos. }\end{array}$ & $\begin{array}{l}\text { - } \\
\text { Sociodemographi } \\
\text { c Data } \\
\text { Questionnaire } \\
\text { (SDQ); } \\
\text {-Beck } \\
\text { Depression } \\
\text { Inventory; } \\
\text { - State-Trait } \\
\text { Anxiety } \\
\text { Inventory } \\
\text { (STAI); } \\
\text { - Barratt } \\
\text { Impulsiveness } \\
\text { Scale, } \\
\text { version 11; } \\
\text {-TCI; } \\
\text { - Adapted } \\
\text { Relationship } \\
\text { Assessment } \\
\text { Scale } \\
\text { (Adapted RAS); } \\
\text { - Love Attitudes } \\
\text { Scale (LAS), } \\
\text { short-form3. }\end{array}$ & $\begin{array}{l}\text {-Grupo clínico: maior } \\
\text { impulsividade, } \\
\text { evitação a danos e } \\
\text { autotranscendência, } \\
\text { maior incidência de } \\
\text { apego ambivalente } \\
\text { ansioso e número } \\
\text { mais elevado de } \\
\text { relações } \\
\text { insatisfatórias. } \\
\text {-Grupo controle: } \\
\text { apego seguro em } \\
\text { maior proporção e } \\
\text { maior número de } \\
\text { relações satisfatórias. }\end{array}$ \\
\hline $\begin{array}{l}\text { Sussman } \\
(2010)\end{array}$ & $\begin{array}{l}40 \text { artigos } \\
\text { científicos }\end{array}$ & $\begin{array}{l}\text { Realizar } \\
\text { revisão da } \\
\text { literatura } \\
\text { sobre } \\
\text { definição, } \\
\text { etiologia, } \\
\text { prevenção e } \\
\text { tratamento } \\
\text { da } \\
\text { dependência } \\
\text { amorosa. }\end{array}$ & Não se aplica & $\begin{array}{l}\text { - Dependência } \\
\text { amorosa: } \\
\text { comportamento } \\
\text { repetitivo voltado } \\
\text { para o objeto de } \\
\text { amor, de modo a } \\
\text { impactar } \\
\text { negativamente a vida } \\
\text { do indivíduo. } \\
\text { - Estimativa: entre } 5 \\
\text { e } 10 \% \text { da população. } \\
\text { - Para prevenção: } \\
\text { identificar pessoas } \\
\text { propensas a }\end{array}$ \\
\hline
\end{tabular}

